\title{
Strong knowledge, weak belief?
}

\section{Moritz Schulz ${ }^{1}$}

Received: 22 December 2020 / Accepted: 24 April 2021 / Published online: 25 May 2021

(c) The Author(s) 2021

\begin{abstract}
According to the knowledge norm of belief (Williamson in Knowledge and its limits, Oxford University Press, Oxford, p. 47, 2000), one should believe $p$ only if one knows $p$. However, it can easily seem that the ordinary notion of belief is much weaker than the knowledge norm would have it. It is possible to rationally believe things one knows to be unknown (Hawthorne et al. in Philos Stud 173:1393-1404, 2016; McGlynn in Noûs 47:385-407, 2013, Whiting in Chan (ed) The aim of belief, Oxford University Press, Oxford, 2013). One response to this observation is to develop a technical notion of 'outright' belief. A challenge for this line of response is to find a way of getting a grip on the targeted notion of belief. In order to meet this challenge, I characterize 'outright' belief in this paper as the strongest belief state implied by knowledge. I show that outright belief so construed allows this notion to play important theoretical roles in connection with knowledge, assertion and action.
\end{abstract}

Keywords Belief $\cdot$ Knowledge $\cdot$ Knowledge-first epistemology $\cdot$ Assertion · Action · Conceptual engineering

\section{Introduction}

Over the last 2 decades, various authors proposed an account of belief in terms of knowledge. ${ }^{1}$ According to Timothy Williamson, belief aims at knowledge:

If believing $p$ is, roughly, treating $p$ as if one knew $p$, then knowing is in that sense central to believing. Knowledge sets the standard of appropriateness for belief. [...] Knowing is in that sense the best kind of believing. Mere believing is a kind of botched knowing. In short, belief aims at knowledge (not just truth) (Williamson 2000, p. 47).

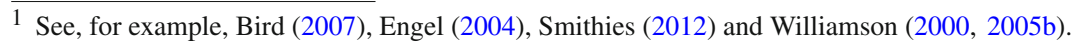

This article belongs to the topical collection on Knowledge First Epistemology, edited by Christoph Kelp and Mona Simion.

Moritz Schulz

moritz.schulz@tu-dresden.de

1 Institut für Philosophie, TU Dresden, 01062 Dresden, Germany 
On this picture, the concept of knowledge is central to our understanding of belief. Belief is either knowledge or a failed attempt at knowledge ("botched knowledge").

The details of how to best capture Williamson's thesis vary. In the quote above, Williamson speaks of a "standard of appropriateness" and of "belief aims at knowledge". This suggests that there is a normative constraint on belief which can be captured in terms of knowledge. Elsewhere Williamson explicitly casts his thesis in terms of 'ought' (Williamson forthcoming). One may therefore capture the constraint as follows:

Knowledge Norm (KN). One ought: believe $p$ only if one knows $p .^{2}$

There are various pieces of evidence the knowledge norm $(\mathrm{KN})$ could explain. ${ }^{3}$ First, it could explain why one should not believe lottery propositions (e.g. Kelp 2014; Sutton 2005: Sec. 4.2; Williamson 2000: p. 58f.; p. 249). Given that one cannot know on probabilistic grounds alone that one's ticket lost, one should not believe that either. Second, it can explain why it seems odd to believe $p$ if at the same time one also believes that one does not know $p$ (Adler 2002: Chap. 1 \& 7; Huemer 2007). Third, the knowledge norm can explain why one can be criticized for believing something one does not know (Sutton 2005: p. 383). One can be criticized because one violates a normative constraint, namely the knowledge norm.

However, various authors object to the knowledge norm by directly challenging the data points just mentioned in its favor (Hawthorne et al. 2016; McGlynn 2013; Whiting 2013). For instance, Aidan McGlynn argues against the knowledge norm by considering a lottery proposition. Suppose a fair lottery was held but the results have not yet been announced. According to McGlynn, one can rationally believe that one's ticket lost. Moreover, one can believe this while simultaneously believing that one does not know that one's ticket lost. Not only is this psychologically possible, but one is not irrational in doing so. If this is true, then the knowledge norm is in great danger. The three data points mentioned in its favor would all rest on a mistake.

While a lottery proposition is something of a close miss, Hawthorne et al. (2016: p. 1400) mention cases where a rational belief may be way off the mark set by anything like knowledge. For Hawthorne et al. (2016), it is perfectly possible that one rationally believes that a certain race horse which is the clear favorite will win even when its chances of winning are below $50 \%$.

\footnotetext{
2 Various authors favor such a knowledge norm, or a close variant of it. In addition to Williamson (2000, 2005b, forthcoming), see e.g. Adler (2002), Bird (2007), Engel (2004), Huemer (2007), Littlejohn (2016, 2020), Smithies (2012), and Sutton (2005, 2007). It is also possible to assume that knowledge is merely a secondary goal of belief while truth is its primary aim (for such a view, see Wedgwood 2002, who follows Williams 1978: pp. 37-45). We may further note that the knowledge norm for belief is stronger than the thesis, defended by Unger (1975: Chap. V), that proper belief must be based on reasons whose propositional content is known.

3 The following three considerations are strictly analogous to considerations put forward by Williamson (1996, 2000) in favor of a knowledge norm for assertion; for the last two of them, see also Unger (1975: Chap. VI). This parallel can be exploited in order to argue for a knowledge norm of belief. If one assumes that impeccable belief permits assertion, and assertion is governed by knowledge, it would follow that belief must be governed by a norm at least as strong as the norm for assertion. This line of argument is explored by Adler (2002: Chap. $1 \&$ 7) and Sutton (2005: Sec. 4.1) (and expanded on in Sutton 2007); see also Bird (2007: p. 95). For criticism, see Littlejohn (2010).
} 
In the light of this, one may suspect that knowledge is strong whereas belief is weak: the epistemic standard required by knowledge is higher than the epistemic standard one should take oneself to satisfy for rationally believing. If one takes rationality to come in degrees, belief being weak would mean that one can be fully rational in believing a proposition without taking oneself to know.

The present kind of objection can be countered in various ways. One prominent line of response highlights certain peculiarities of belief ascriptions. For instance, Jason Stanley notes that phrases such as 'I believe' can be used to hedge one's assertion:

However, the function of using "I believe" in ["I believe that dogs bark, but I don't know it"] is to qualify support for the truth of a proposition, rather than endorse it. In short, such uses of "believe" are not cases in which one reports a belief that $\mathrm{p}$ at all; they are rather cases in which one reports that one has weak reasons in support of the truth of a proposition (Stanley 2008, p. 51f.).

On this view, one weakens rather than strengthens one's assertion if one says 'I believe the party is tomorrow' instead of saying 'The party is tomorrow'. Based on this observation, one may suspect that phrases such as 'I believe' or 'I think' do not always serve to self-ascribe a belief. At least in some situations, they would be used in a non-literal sense to hedge one's assertions.

It is debatable, though, how strong this defense is. For there is the question of why a phrase such as 'I believe' can be used to hedge one's assertions. Thus, Hawthorne et al. (2016: p. 1397) complain that "[...] the non-literality of 'belief' in these cases does not cohere with any systematic pragmatic story we know about 'belief'." In contrast, a particularly straightforward explanation of epistemic hedging in terms of 'I believe' would be to say that hedging is possible simply because belief is weak and requires less than is needed for unqualified assertion. A second issue for Stanley's hypothesis is that if 'believe' has a literal as well as a non-literal meaning, one would expect to find cases in which one can ascribe belief in the weak sense and deny belief in the strong case. As Hawthorne et al. (2016: p. 1399) ague, such cases are very hard to find.

If successful belief is weaker than what knowledge requires, is the knowledge norm for belief just false? This seems to be what McGlynn (2013) and Whiting (2013) think. Hawthorne et al. (2016) concur, provided the knowledge norm is concerned with our ordinary notion of belief. But they also suggest that the knowledge norm could be construed in terms of a technical notion of belief:

\footnotetext{
In the philosophy literature one often sees reference to 'outright belief' or 'full belief'. The main use in the literature of these terms is to distinguish merely believing something probable from believing simpliciter. This may be a useful theoretical notion distinct from certainty and sureness, and it may be one for which norms comparable to those for assertion apply. However, our arguments above indicate that this notion is not a disambiguation of what we ordinarily mean by 'belief'; rather it seems a theoretical posit. Thus, those arguing for the importance of outright or full belief as a notion stronger than ordinary belief but distinct from believing or being certain cannot argue for it on the basis of its commonsense status as grounded in our talk about belief. The everyday notion of belief is a weak one (Hawthorne et al. 2016, p. 1402).
}

Taking 'outright belief' to be a technical notion opens up a possible defense of the knowledge norm for belief. Although the knowledge norm would not hold for our ordinary notion of belief, it could hold for a technical notion of belief that is shaped by theoretical considerations. 
However, it may seem that being concerned with a technical notion of belief would bereave the knowledge norm of much of its interest. The purpose of this paper is to show that this is not so. It can make sense to work with a theoretical notion of belief in philosophy just like it can make sense to work with a theoretical notion of mass in physics. What is true, however, is that responding to the worries about the knowledge norm with a technical notion of belief raises important challenges.

One question about this defense is: how does one get a grip on a theoretical notion of belief if not through one's understanding of the ordinary notion? Thus, McGlynn objects to the idea of rescuing the knowledge norm by appeal to 'outright' belief as follows:

[...] the distinction between fully believing something and merely believing it to a high degree is vague. That doesn't render it unserviceable or insignificant of course, but it should make us nervous about putting as heavy weight on it as the suggestion under consideration does (McGlynn 2013, p. 389).

I agree with McGlynn that the distinction between 'outright' beliefs and 'belief' in its ordinary sense will be vague. There may not be a clearly identifiable line which demarcates 'outright' beliefs from ordinary beliefs which are firmly held but may fall short of counting as 'outright' beliefs. But as McGlynn seems to acknowledge, vagueness is not in and of itself a problem. After all, almost any philosophically interesting expression seems to be vague to some degree.

However, given that the knowledge norm of belief is thought to take center place in a "knowledge first"-epistemology, it is particularly important for 'outright belief' to be well defined. For the main part, I shall therefore indicate in this paper how one can get a grip on a theoretical notion of belief which is strong enough to satisfy something like the knowledge norm. I will do so by describing three roles a theoretical notion of belief should play. These three roles concern the relation between belief on the one hand and knowledge, assertion and action on the other.

\section{Belief and knowledge}

Knowledge implies belief, or so I shall assume for the purposes of this paper (for opposition, see Radford 1966 and Myers-Schulz and Schwitzgebel 2013). But if belief is weak, knowledge will imply more than just (weak) belief. If I know of a given lottery ticket that it lost, I am in a stronger belief state than when I merely believe this on probabilistic grounds alone.

To vary this thought, suppose I believe that the favorite in the Kentucky Derby is Morning Star, and the odds show her far ahead of the competition. However, given the total size of the competition, the chances of Morning Star winning the Derby may still only be around 50\%. If belief is weak, my belief that Morning Star will win may well be rational despite falling short of knowledge by a large margin. So, when I actually come to know that Morning Star will win, either because I witnessed the race or was told about the outcome, I will continue to have the same belief but I am now entitled to be much more confident about it. 
From this, I think, one can infer that knowledge implies strong belief. By this I mean that the kind of belief state implied by knowledge is a belief state one is only entitled to if one is in a stronger epistemic position than what entitles one to ordinary weak belief. In other words, the belief state implied by knowledge is a belief state which requires a stronger justification than ordinary weak belief.

If this is right, then there is a possible pathway of characterizing outright belief in relation to knowledge:

Belief and knowledge. Outright belief is the strongest belief state implied by knowledge. ${ }^{4}$

A few words on how this proposal is to be understood. In an obvious manner, outright belief is characterized as a species of ordinary belief. Not all cases of ordinary belief will, on this proposal, count as cases of outright belief. But all cases of outright belief will count as cases of ordinary belief. Thus, 'outright' modifies 'belief' in a way similar to how 'fast' modifies 'run'.5

A second aspect of the proposal is that it proceeds in terms of implication. Belief states of various strength are compatible with knowledge. So, there is no single kind of belief so that all instances of knowledge are accompanied by a belief state of that strength. For this reason, the idea behind the proposal is to look at the minimal strength a belief state must have for the belief state to count as knowledge. The strongest belief state implied by knowledge is a belief state minimally required by knowledge.

The present proposal presupposes that belief states can be ranked according to their strength. One may naturally ask what kind of strength is in play here. As the proposal would gain from staying as neutral on the nature of ordinary belief as possible, the strength of belief states should be given, I think, only a minimal account (for a more substantive proposal, see Schulz (forthcoming). One way of staying largely neutral in this regard would be to say that the strength of a belief corresponds to the strength of the epistemic standard one must satisfy for the belief to be properly held. Some may wish to understand epistemic standards in terms of justification. Others would perhaps like to draw on probability or reliability. But in order to characterize a notion of outright belief, it might be best to leave this as a substantial question whose answer is not backed into the notion itself.

The present proposal also presupposes that we have a grip on what a belief state is. It is important for this proposal that belief states are what we intuitively take them to be. It would be fatal if true belief or justified belief or even belief constituting knowledge could turn out to be a belief state, because then the strongest belief state implied by knowledge would not be the kind of outright belief I take it to be. ${ }^{6}$

On a pre-theoretical level, there should be little doubt that we have a grip on what a belief state is. We are all competent users of the term 'believe'. Hence, we may say that a belief state is any state ascribed by 'believe' (in at least some context). Finer

\footnotetext{
4 A similar proposal is briefly sketched by Schulz and Rosenkranz (2015: p. 558).

5 Thus, the proposal is not to change (or engineer) our ordinary notion of belief as Chalmers and Clark (1998) do with respect to the "extended mind". The only thing which changes is that we introduce a technical term ('outright') to our language which is allowed to qualify 'belief'.

6 Thanks to an anonymous referee for raising this worry.
} 
distinctions which single out subclasses of belief-strong or weak-can in turn be made by ranking belief states in terms of their strength.

If instead one prefers a more theory-driven characterization of belief states, one should turn to the nature of belief itself and discern some variable element in it. For example, if one's theory of belief contains a clause requiring a certain level of firmness, one can find room for belief states of various strength by allowing this level of firmness to vary. Similarly, if one's theory of belief contains a clause requiring that one is prepared to rely on the proposition in question to a certain degree in one's decision-making, one may generalize this clause by letting the degree of reliance vary.

If one ties all this together, one may be able to offer an alternative formulation of what it is to outrightly believe. One would outrightly believe a proposition $p$ iff one is in a belief state which is subject to an epistemic standard $S$, where $S$ is the strongest epistemic standard imposed by knowledge. Knowledge would be taken to require a certain epistemic standard. Belief states would be taken to vary according to which epistemic standard they are subject to. Outright belief would be identified as the belief state which is subject to the (strongest) epistemic standard required by knowledge.

Characterizing outright belief as a belief state that is more demanding than ordinary weak belief allows outright belief to serve a certain explanatory role. Knowledge has a subjective aspect. There is the question of 'how knowledge feels from inside'. More specifically, one would like to be able to account for why agents behave the way they do when they fail to know while they are in a state which is internally indiscriminable from knowledge (e.g. they have a Gettiered belief). On the present proposal, outright belief can fill this gap. Outright belief captures the subjective aspect of knowledge; it is 'how knowledge feels from inside'. Moreover, one can appeal to the fact that an agent had an outright belief in order to explain why the agent acted as if they knew even though they did not in fact know but rather were in a state internally indiscriminable from knowledge.

A potential objection to the present proposal could be that it might look as if it trivializes the knowledge norm for belief. If one characterizes outright belief in terms of knowledge, is it still informative to say that outright belief aims at knowledge?

It seems clear, though, that this question should be answered affirmatively. For most philosophers, knowledge implies belief. Still, many also think that belief does not aim at knowledge but rather at truth (see e.g. Whiting 2012). Thus, it is perfectly coherent to hold that belief is implied by knowledge but does not aim at knowledge. The coherence of this claim does not go away if instead one were to hold that the strongest belief state implied by knowledge does not aim at knowledge (but, say, at truth). Thus, characterizing outright belief in terms of knowledge does not trivialize the claim that outright belief aims at knowledge.

What the proposal does, however, is to take one reason for rejecting the knowledge norm away. If one rejects the knowledge norm solely on the grounds that belief is weak, then one no longer has a reason to reject the knowledge norm when it is cast in terms of outright belief.

McGlynn has a further objection to the present proposal (one may read 'full belief' as 'outright belief' in this quote): 
I think I fully believe that my car hasn't been stolen overnight—or at least, I'm as confident about that as I am about most of my other beliefs about contingent matters. Unless the proposal is that full belief is a state we rarely succeed in getting ourselves into, I have a hard time seeing why we should hold that I don't fully believe that my car hasn't been stolen. So we're owed an account of what distinguishes my belief that my ticket will lose from my belief that my car hasn't been stolen, such that we might be warranted in taking the latter, but not the former, to be a full belief. I don't claim to have ruled out the possibility of such an account, but it seems to me that we can justifiably remain sceptical (McGlynn 2013, p. 389).

I take McGlynn's objection to go as follows. If the notion of outright belief is not too demanding, then we will have many outright beliefs, including beliefs such as the one McGlynn mentions. But it may seem that we are as confident about these beliefs as we are about lottery propositions. If one holds that beliefs concerning lottery propositions do not count as outright beliefs when the belief is based on probabilistic grounds alone, then it seems unclear how one can classify as 'outright' the belief that one's car has not been stolen overnight.

For present purposes, let us assume that we can know in the relevant circumstances that our car has not been stolen while we cannot know that our lottery ticket lost. It is a difficult question why knowledge is distributed in this way; unfortunately, this question is beyond the scope of the present paper. But given that outright belief has been tied to knowledge, the fact that knowledge is distributed unequally over the relevant cases is a promising starting point to address McGlynn's worry.

If we assume that the relevant propositions are both true, then the fact that knowledge is unavailable in the lottery case but possible in the car case indicates that the proposition expressed by 'My car has not been stolen overnight' is epistemically better off than the proposition expressed by 'My lottery ticket lost'. Hence, there seems to be an epistemic dimension of comparison along which the lottery proposition rates worse than the car proposition. We may presently be somewhat in the dark about the exact nature of this dimension of comparison. The relevant comparisons may have something to do with the fact that a belief in the car proposition would be safe while a belief in the lottery proposition would not be. ${ }^{7}$ They could also have something to do with the fact that it is normal that one's car is not stolen while it is not normal that one's lottery ticket wins. ${ }^{8}$ Whatever the right explanation of these cases is, the very fact that knowledge is distributed unevenly is evidence that there is a salient dimension of epistemic comparison according to which the knowledgeable belief comes out ahead.

The assumption that there is such a dimension of comparison is compatible with the existence of other dimensions of comparisons according to which the two beliefs would be on a par or the order would even be reversed. For example, we may look at the expected frequency of truth in the two cases. Given that sometimes cars are stolen overnight, there will be lotteries such that a belief that one's ticket lost will be true roughly as often as a belief that one's car has not been stolen overnight. Hence, one can grant that according to some standards of evaluation, the car belief is not better than the lottery belief. What one needs to insist on, however, is that along the dimension of comparison salient in our ascriptions of knowledge, the car belief is stronger than the lottery belief.

\footnotetext{
7 On the notion of safety, see e.g. Pritchard (2005), Sosa (1999) and Williamson (2000: Chap. 5).

8 On normalcy in this context, see Smith (2016).
} 
To summarize, outright belief has been characterized as the strongest belief state which is implied by knowledge. On this proposal, outright belief is a species of ordinary belief which is required to be somewhat stronger than what is minimally required for ordinary belief. Outright belief so understood allows one to describe the subjective aspect of knowledge and helps to explain the behavior of agents who hold beliefs that fail to be knowledge but which are internally indiscriminable from knowledge. Thus, we get a grip on the notion of outright belief by employing our understanding of the ordinary notion of belief and combining it with the concept of knowledge. By way of analogy, introducing 'outright belief' into our language by appeal to knowledge may be compared to introducing 'fast run' by appeal to high speed into a language which contains already 'run' but not yet 'fast'.

\section{Belief and assertion}

If belief is weak, then the standards for assertion are higher than the standards for ordinary belief. As Hawthorne et al. (2016: p. 1394) put it: “[...] the evidential standards for assertion, whatever they are, are much higher than those for belief." For instance, if Morning Star is the clear favorite, it may be fine to believe that Morning Star will win the Kentucky Derby even when its chances of winning are only around 50\%. But it would be odd to flat-out assert 'Morning Star will win', except perhaps when it is clear that one is just naming one's favorites. The same goes for lottery propositions (cf. e.g. Smithies 2012; Williamson 2000: p. 246f.). It seems odd to assert on probabilistic grounds alone:

(1) My ticket lost.

Asserting this proposition naturally invites questions like 'How do you know?' or 'How can you be sure?'. When asserting that one's ticket lost on probabilistic grounds alone, it seems one presents oneself to be in a better epistemic position than one really is.

Further support for the claim that the standards for proper assertion are higher than those for weak ordinary belief comes from considering Moorean sentences:

(2) I believe my ticket lost but of course I do not know this.

(3) My ticket lost but of course I do not know this.

The second of these two sentences combines an assertion of $p$ with a denial that one knows $p$. It is commonly considered to be an incoherent thing to say (Unger 1975: Chap. VI; Williamson 1996, 2000). At the same time, the first of the two sentences sounds fine, or at least much better (Whiting 2013). If belief is weak, this is what one would expect as one could rationally believe $p$ while believing or even knowing that one does not know $p$.

Thus, if belief is weak, we do not share or express our beliefs when we assert something. Or at least, expressing a weak ordinary belief would not fully capture the mental state that we express when we make an assertion. In asserting something, we would present ourselves to be in a stronger state than what is required by a weak ordinary belief. Moreover, satisfying the standards for proper belief would in general 
be insufficient for proper assertion. That is, what Hawthorne et al. (2016: p. 1394) dub entitlement equality would be false: one is not entitled to belief iff one is entitled to assertion.

If this is so, then there is a theoretical gap in our account of assertion. What kind of mental state do we express when we make an assertion? What kind of mental state could satisfy the thesis of entitlement equality? I contend that the notion of outright belief naturally fills this gap (cf. Adler 2002: p. 231, although Adler does not seem to think that our ordinary notion of belief is weak). On the present proposal, outright belief could be the subjective attitude we express when we make an unqualified assertion.

Moreover, outright belief is a plausible candidate to accommodate a version of entitlement equality. Given that the notion of outright belief has been introduced as the strongest belief state implied by knowledge, it is plausible to hold that one is entitled to a proper belief iff one is entitled to proper assertion. (As I shall explain in a moment, entitlement must be taken in a purely epistemic sense here, for proper assertion is also subject to non-epistemic considerations.) One way of arguing for entitlement equality would be to argue for a knowledge norm of assertion (cf. Unger 1975: Chap. VI; Williamson 1996, 2000) and a knowledge norm for outright belief. Knowing would then be what entitles one to outright belief as well as to assertion. It is noteworthy, though, that this is not the only way of establishing entitlement equality. One could also argue that being justified to outrightly believe $p$ entitles one to belief as well as to assertion (cf. Lackey 2007).

If one wishes, one may even try to characterize outright belief in terms of assertion. The thought would be that having an outright belief comes or even coincides with a defeasible disposition for flat-out assertion in relevant circumstances. This thought requires some unpacking, for various pragmatic factors can interfere with this disposition. For proper assertion, one's belief must satisfy a great variety of further pragmatic constraints: it must be relevant, it should not insult anyone, etc. But it must also be the case that one does not have personal reasons for withholding either because one's belief is top secret or one has reason to lie.

In light of all these caveats, I take it to be the superior option to introduce outright belief as the strongest belief state implied by knowledge, while the link between belief and assertion is something which gets subsequently explained in terms of outright belief so understood. Thus, outright belief would not be characterized in terms of assertion. Rather, it would serve to explain, for example, why someone is disposed to assert a proposition which she does not in fact know even though everything appears as if she knew.

In sum, if belief is weak, the epistemic standards for proper assertion and for proper belief come apart. This raises the question of what mental state we express in assertion. In this section, I argued that outright belief conceived of as the strongest belief state implied by knowledge can play the desired role. Outright belief is what we express in assertion. And it is plausible that outright belief so conceived satisfies entitlement equality: the standards for proper outright belief are the standards for proper assertion. 


\section{Belief and action}

Belief serves a practical purpose. For example, Williamson (2000: p. 99) claims: "Intuitively, one believes $p$ outright when one is willing to use $p$ as a premise in practical reasoning." A willingness to use $p$ as a premise in practical reasoning can be understood as a disposition to reason from $p$ in decision situations in which the question of whether $p$ is considered relevant. In a similar vein, Jakob Ross and Mark Schroeder (2014) give an account of believing $p$ according to which a belief is a defeasible disposition to treat $p$ as true in one's practical deliberations. On the proposals by Williamson as well as by Ross and Schroeder, belief serves an important function for practical reasoning. One is prepared to rely on those propositions one believes to be true when one deliberates about what to do (see also Schulz forthcoming; Weatherson 2005; Wedgwood 2012).

The present connection between belief and practical reasoning is descriptive: belief comes with or may even consist in a disposition to rely on the believed propositions in practical reasoning. Similar to the case of assertion, it is plausible that there is also a normative connection: the standards for proper belief equal the standards for proper reliance. If part of the function of belief is to provide premises for one's practical reasoning, one would expect that believing $p$ is proper iff relying on $p$ is proper. According to the envisaged normative claim, it is appropriate to believe $p$ iff it would be appropriate to adopt $p$ as a premise in practical reasoning. (This parallels the assumption of entitlement equality discussed in the previous section.)

However, if belief is weak, both the descriptive and the normative thesis are false. This can perhaps best be seen by considering a lottery proposition. If belief is weak, one can properly believe that one's ticket lost on probabilistic grounds alone. But this belief does not come, and should not come, with a willingness to treat the lottery proposition as true in one's practical reasoning (cf. Hawthorne 2004: p. 29f.; Hawthorne and Stanley 2008: p. 572). For otherwise one would be prepared to throw one's ticket away. After all, if one's ticket lost, it is - special circumstances aside-a reasonable decision to throw one's ticket away. So, if one were prepared to adopt the lottery proposition as a premise in one's practical reasoning, one could soundly reason to the conclusion that the ticket can be thrown away. But if the lottery proposition is believed on probabilistic grounds alone, then we are not willing to reason in this way, nor should we be willing to reason in this way.

The descriptive thesis as well as the normative thesis can be restored if instead of ordinary weak belief they are cast explicitly in terms of outright belief. The strongest belief state implied by knowledge plausibly comes with a disposition to yield input premises to one's practical reasoning. Moreover, the standards for proper outright belief can plausibly be taken to coincide with the standards for proper reliance in practical reasoning. Of course, establishing the descriptive as well as the normative thesis requires more than supplying a notion of belief which is strong rather than weak. The point here is merely that characterizing outright belief in the described way shields the two theses from an objection based on the observation that ordinary belief is weak. 
Similar to the case of assertion, the normative thesis could be true because there is a knowledge norm for belief as well as a knowledge norm for practical reasoning. ${ }^{9}$ But as before, this is not forced by the described notion of outright belief itself. One may construe outright belief as the strongest belief state implied by knowledge, yet hold that justification rather than knowledge is what underwrites proper belief as well as proper reliance in practical reasoning.

In sum, outright belief can play an important explanatory role in describing the link between belief and action. The notion of outright belief helps to delineate the class of beliefs which provide the premises of our practical reasoning. It further supplies the material to state a corresponding normative connection between our beliefs and those propositions we should rely on in practical reasoning.

\section{Concluding remarks}

According to the knowledge norm for belief, one should believe $p$ only if one knows $p$. Various considerations about our ordinary notion of belief indicate that belief may be much weaker than the knowledge norm would have it. It seems we can rationally believe various propositions, including lottery propositions, that we know to be unknown. If one takes the underlying data at face value, then belief is weak while knowledge is strong: the epistemic standards required by knowledge are much higher than those required for proper belief.

In this paper, I have developed one line of response which is compatible with our ordinary notion of belief being weak. According to this kind of response, the knowledge norm should be taken to pertain to a partly technical notion of 'outright' belief. This notion is not wholly technical because 'outright' beliefs are still beliefs in the ordinary sense. Yet it is partly technical because one is prepared to accept that 'outright' in 'outright belief' modifies belief in a way shaped by theoretical considerations. I have suggested to characterize outright belief as the strongest belief state implied by knowledge.

One advantage of going in for a technical notion of outright belief is that one is no longer hostage to linguistic fortune. Should it turn out, however, that the ordinary notion of belief is strong after all, one could still happily accept that outright belief just is belief in the ordinary sense. This could happen, for instance, if the data favoring weak belief turn out to be not fully genuine, either because they invoke a non-literal use of 'believe' as Stanley (2008) contends or because we are speaking loosely when we ascribe belief on weak grounds as Sara Moss (2019) has recently argued.

On a technical construal, outright belief is evidently not weak but strong. In this way, outright belief becomes a plausible candidate for satisfying the knowledge norm for belief, or at least considerations about the strength of belief no longer stand in the way of the knowledge norm for belief. Outright belief characterized in this way is also of the right strength to underwrite plausible descriptive as well as normative links between belief and assertion as well as between belief and action. In this way,

\footnotetext{
9 For knowledge norms on practical reasoning, see amongst others Fantl and McGrath (2002), Hawthorne (2004), Hawthorne and Stanley (2008), Hyman (1999), Schulz (2017, forthcoming), Smithies (2012), Unger (1975: p. 200f.), and Williamson (2000, 2005a, 2017).
} 
it becomes possible to hold that the standards for proper belief and proper assertion on the one hand, as well as the standards for proper belief and proper reliance on the other hand, all coincide.

Acknowledgements I would like to thank two anonymous referees for Synthese for their helpful comments. This work was supported by the Deutsche Forschungsgemeinschaft under Grant SCHU 3080/3-1/2/3 and was conducted within the Emmy-Noether research group 'Knowledge and Decision'. Many thanks to all its participants!

Funding Open Access funding enabled and organized by Projekt DEAL.

Open Access This article is licensed under a Creative Commons Attribution 4.0 International License, which permits use, sharing, adaptation, distribution and reproduction in any medium or format, as long as you give appropriate credit to the original author(s) and the source, provide a link to the Creative Commons licence, and indicate if changes were made. The images or other third party material in this article are included in the article's Creative Commons licence, unless indicated otherwise in a credit line to the material. If material is not included in the article's Creative Commons licence and your intended use is not permitted by statutory regulation or exceeds the permitted use, you will need to obtain permission directly from the copyright holder. To view a copy of this licence, visit http://creativecommons.org/licenses/by/4.0/.

\section{References}

Adler, J. E. (2002). Belief's own ethics. New York: MIT Press.

Bird, A. (2007). Justified judging. Philosophy and Phenomenological Research, LXXILXXIV, 81-110.

Chalmers, D., \& Clark, A. (1998). The Extended Mind. Analysis, 58, 7-19.

Engel, P. (2004). Truth and the aim of belief. In D. Gillies (Ed.), Laws and models in science (pp. 77-97). London: King's College Publications.

Fantl, J., \& McGrath, M. (2002). Evidence, pragmatics, and justification. The Philosophical Review, CXI, $67-94$.

Hawthorne, J. (2004). Knowledge and lotteries. Oxford: Oxford University Press.

Hawthorne, J., Rothschild, D., \& Spectre, L. (2016). Belief is weak. Philosophical Studies, 173, 1393-1404.

Hawthorne, J., \& Stanley, J. (2008). Knowledge and action. The Journal of Philosophy, 105, 571-90.

Huemer, M. (2007). Moore's paradox and the norm of belief. In S. Nuccetelli \& G. Seay (Eds.), Themes from G. E. Moore, Oxford: Oxford University Press, pp. 142-57.

Hyman, J. (1999). How knowledge works. Philosophical Quarterly, XLIX, 433-51.

Kelp, C. (2014). No justification for lottery losers. Pacific Philosophical Quarterly, 95, 205-17.

Lackey, J. (2007). Norms of assertion. Noûs, 41, 594-626.

Littlejohn, C. (2010). Moore's paradox and epistemic norms. Australasian Journal of Philosophy, 88, 79100.

Littlejohn, C. (2016). Who cares what you accurately believe? Philosophical Perspectives, 29, 217-48.

Littlejohn, C. (2020). On what we should believe (and when (and why) we should believe what we know we should not believe). In K. McCain \& S. Stapleford (Eds.). Epistemic duties, Routledge.

McGlynn, A. (2013). Believing things unknown. Noûs, 47, 385-407.

Moss, S. (2019). Full belief and loose speech. Philosophical Review, 128, 255-91.

Myers-Schulz, B., \& Schwitzgebel, E. (2013). Knowing that P without believing that P. Noûs, 47, 371-84.

Pritchard, D. (2005). Epistemic luck. Oxford: Oxford University Press.

Radford, C. (1966). Knowledge-by examples. Analysis, 27, 1-11.

Ross, J., \& Schroeder, M. (2014). Belief, credence, and pragmatic encroachment. Philosophy and Phenomenological Research, LXXXVIII, 259-88.

Schulz, M. (2017). Decisions and higher-order knowledge. Noûs, 51, 463-83.

Schulz, M. (forthcoming). Practical reasoning and degrees of outright belief. In R. Heil, J. Koscholke, P. Rich, \& M. Schulz (Eds.), Synthese topical collection "knowledge and decision".

Schulz, M., \& Rosenkranz, S. (2015). Peer disagreement: a call for the revision of prior probabilities. Dialectica, 69, 551-86.

Smith, M. (2016). Between probability and certainty. Oxford: Oxford University Press. 
Smithies, D. (2012). The normative role of knowledge. Noûs, 46, 265-88.

Sosa, E. (1999). How to defeat opposition to moore. Noûs, 33, 141-53.

Stanley, J. (2008). Knowledge and certainty. Philosophical Issues, 18, 35-57.

Sutton, J. (2005). Stick to what you know. Nô̂s, 39, 359-96.

Sutton, J. (2007). Without justification. New York: MIT Press.

Unger, P. (1975). Ignorance: A case for scepticism. New York: Oxford University Press.

Weatherson, B. (2005). Can we do without pragmatic encroachment? Philosophical Perspectives, 19, $417-$ 43.

Wedgwood, R. (2002). The aim of belief. Philosophical Perspectives, 16, 267-97.

Wedgwood, R. (2012). Outright belief. Dialectica, 66, 309-29.

Whiting, D. (2012). Does belief aim (only) at the truth? Pacific Philosophical Quarterly, 93, 279-300.

Whiting, D. (2013). Nothing but the truth: On the norms and aims of belief. In T. Chan (Ed.), The aim of belief (pp. 184-203). Oxford: Oxford University Press.

Williams, B. (1978). Descartes: The project of pure enquiry. Harmondsworth: Penguin Books.

Williamson, T. (1996). Knowing and asserting. Philosophical Review, 105, 489-523.

Williamson, T. (2000). Knowledge and its limits. Oxford: Oxford University Press.

Williamson, T. (2005a). Contextualism, subject-sensitive invariantism and knowledge of knowledge. The Philosophical Quarterly, 55, 213-35.

Williamson, T. (2005b). Knowledge, context and the agent's point of view. In G. Preyer \& G. Peter (Eds.), Contextualism in Philosophy (pp. 91-114). Oxford: Oxford University Press.

Williamson, T. (2017). Acting on knowledge. In A. J. Carter, E. Gordon, \& B. W. Jarvis (Eds.), Knowledge first (pp. 163-81). Oxford: Oxford University Press.

Williamson, T. (forthcoming). Non-modal normativity and norms of belief. Acta Philosophica Fennica.

Publisher's Note Springer Nature remains neutral with regard to jurisdictional claims in published maps and institutional affiliations. 